www.jmscr.igmpublication.org

Impact Factor 5.84

Index Copernicus Value: 71.58

ISSN (e)-2347-176x ISSN (p) 2455-0450

crossref DOI: _https://dx.doi.org/10.18535/jmscr/v5i12.69

Journal Of Medical Science And Clinical Research

\title{
A Comparative Study of Surgically Induced Astigmatism in Various Incisions in Manual Sutureless Small Incision Cataract Surgery
}

\author{
Authors \\ Dr Rajkumar Patra ${ }^{1}$, Dr Vinayak Ganesh Bhat ${ }^{2}$, Dr Suryachandra Mallireddy ${ }^{2 \#}$ \\ ${ }^{1}$ Senior Resident, Department of Ophthalmology, RIMS, Srikakulam \\ ${ }^{2}$ Consulant, Srikakulam \\ ${ }^{2 \#}$ Assistant Professor, Department of Ophthalmology, RIMS, Srikakulam
}

\begin{abstract}
Objective: To determine surgically induced astigmatism (SIA) in Chevron (inverted V shape), frown, Boat shaped and straight incisions in manual small incision cataract surgery conducted in patients admitted in RIMS, Srikakulam.

Material and Methods: study was conducted in patients getting admitted for cataract surgery in Rajiv Gandhi Institute of medical Sciences, Srikakulam, Andhra Pradesh. 100 patients were randomly selected who are above 40 years of age and senile cataract. They were divided into 4 groups with 25 each in each group. All four groups underwent similar manual incision cataract surgery with carefully placed intraocular lenses. Only difference between 4 groups is the type of incision during the beginning of cataract surgery. Patients were compared 6 weeks post operatively for uncorrected visual acuity (UCVA), best corrected visual acuity (BCVA) and surgically induced astigmatism. The datas obtained were tabulated and analyzed statistically using paired and unpaired t test and chi square test using SPSS version 17 software.

Observation: In our study Chevron incision produced minimal astigmatism with maximum patients (48\%) with astigmatism between 0.5-1D. Followed by (36\%) in 0.6-1D. Frown and boat shaped incisions showed almost similar results. There was significantly small difference between them which was negligible. in Frown incision maximum patients (44\%) had astigmatism 1.1-1.5D followed by(28\%) 0.5 1D. in boat shaped incision maximum patients(36\%) were seen in 1.1-1.5D followed by(28\%) 0.5-1D. straight incision showed significantly higher astigmatism with maximum patients (40\%) between 1.1$1.5 D$.

Conclusion: Chevron incision (inverted $V$ incision) induced significantly less surgically induced astigmatism followed by frown incision and boat shaped incision. Straight incision caused maximum surgically induced astigmatism.

Keyword: surgically induced astigmatism, chevron incision, frown incision, boat shaped incision, straight incision, MSICS, comparitive study.
\end{abstract}

\section{Introduction}

With the introduction of phacoemulsification in cataract surgery which requires only $3 \mathrm{~mm}$ incision, need for manual small incision cataract surgery (SICS) is drastically decreased. Even the surgically induced astigmatism (SIA) is drastically minimal. But as phacoemulsification being cost effective in developing country like India, still the 
need for SICS in evident ${ }^{[1-4]}$. It is also better suited and cost effective for advanced and maturecataracts seen in developing countries ${ }^{[5-7]}$. There are plenty of studies done to tell the astigmatic difference between SICS and Phacoemulsification. But not many studies are done to tell difference between different types of incisions during small incision cataract surgery and the astigmatism produced by respective methods. Some previous studies have analyzed the best site for incision and the surgically induced astigmatism $^{[8-12]}$. Similarly this cross sectional study focuses on the differences between different incisions on randomly selected patients who otherwise went similar methods of cataract surgery except the types of incisions given. Their 6 week post operative vision was noted.

\section{Material and Methods}

This is a randomized control trial. This study included 100 patients admitted in Rajiv Gandhi institute of medical sciences, Srikakulam for cataract surgery. They all were above 40 years with uncomplicated senile cataract till grade 3 nuclear sclerosis. Hard cataract and nuclear cataract grade 4 was excluded in the study. Cataract with complications like subluxated lens, pseudoexfoliation, preexisting retinal and corneal diseases were also excluded. randomization was done through NCBI approved site www.graphpad.com/quickcals/randomize2/

List for randomization was made and put up. Every new patient came to hospital, strictly patient was assigned as per the chart. It was overlooked personally by us to keep randomization unbiased.
Sample was kept 100 to keep quality intact in given short time span as reference to many other studies ${ }^{14,16}$.The sample size for this study was determined by statistician of our college using the following formula $n=\left(Z_{\alpha / 2}+Z_{\beta}\right)^{2} * 2 * \sigma^{2} / d^{2}$. By this formula sample size was decided to be 25 in each group to minimize errors and have statistical significance.

These 100 patients were divided into 4 groups named group S (straight), Group B(Boat shaped), Group F (Frown) and Group C (Chevron) randomly. Detailed evaluation of the cases was carried out like slit lamp biomicroscopy, tonometry, lacrimal sac syringing, fundus examination, keratometry and A-scan biometry. Pre operative emphasis was laid on keratometry and A-scan which was done for both eyes. Patients were posted for surgery on the next day and operated. Intraocular lens (IOL) power was calculated using SRK II formula.

During the surgery it was made sure all the other steps of manual small incision cataract surgery will be the same except for the incision made at the sclera. Incisions were $6 \mathrm{~mm}$ in cord length. The incision were taken $2.5-3 \mathrm{~mm}$ posterior to limbus. Sclerocorneal tunnel with formation of corneal valve was made. Continuous curvilinear capsulorrhexis was done in all cases. Viscoelastics were used generously. Minimal iris handling was ensured. In-the-bag placement of IOL was done. Patient vision were analysed at the $6^{\text {th }}$ week post operative period. The results obtained were tabulated and analyzed statistically by our statistician using paired and unpaired t test and chi square test using SPSS version 17 software.

\section{Observations}

100 eyes of 100 patients were observed in this study. Here patients were of different age group as below.

\begin{tabular}{|l|c|c|c|c|}
\hline AGE & No of patients & Gender & Percentage & Gender \\
\hline $51-60$ & 23 & M- 15 & \multirow{2}{*}{$23 \%$} & M- $15 \%$ \\
\cline { 3 - 3 } & & F- 8 & & F- 8\% \\
\hline \multirow{2}{*}{$61-70$} & 46 & M- 29 & \multirow{2}{*}{$46 \%$} & M- 29\% \\
\cline { 3 - 3 } & & F- 17 & & F- $17 \%$ \\
\hline $71-80$ & 31 & M- 20 & \multirow{2}{*}{$31 \%$} & M- 20\% \\
\cline { 3 - 3 } & & F- 11 & & F- $11 \%$ \\
\hline
\end{tabular}

M- Male F-Female.

The chi-square statistic is 0.0366 . The p-value is .981844 . The result is not significant at $\mathrm{p}<.05$. 


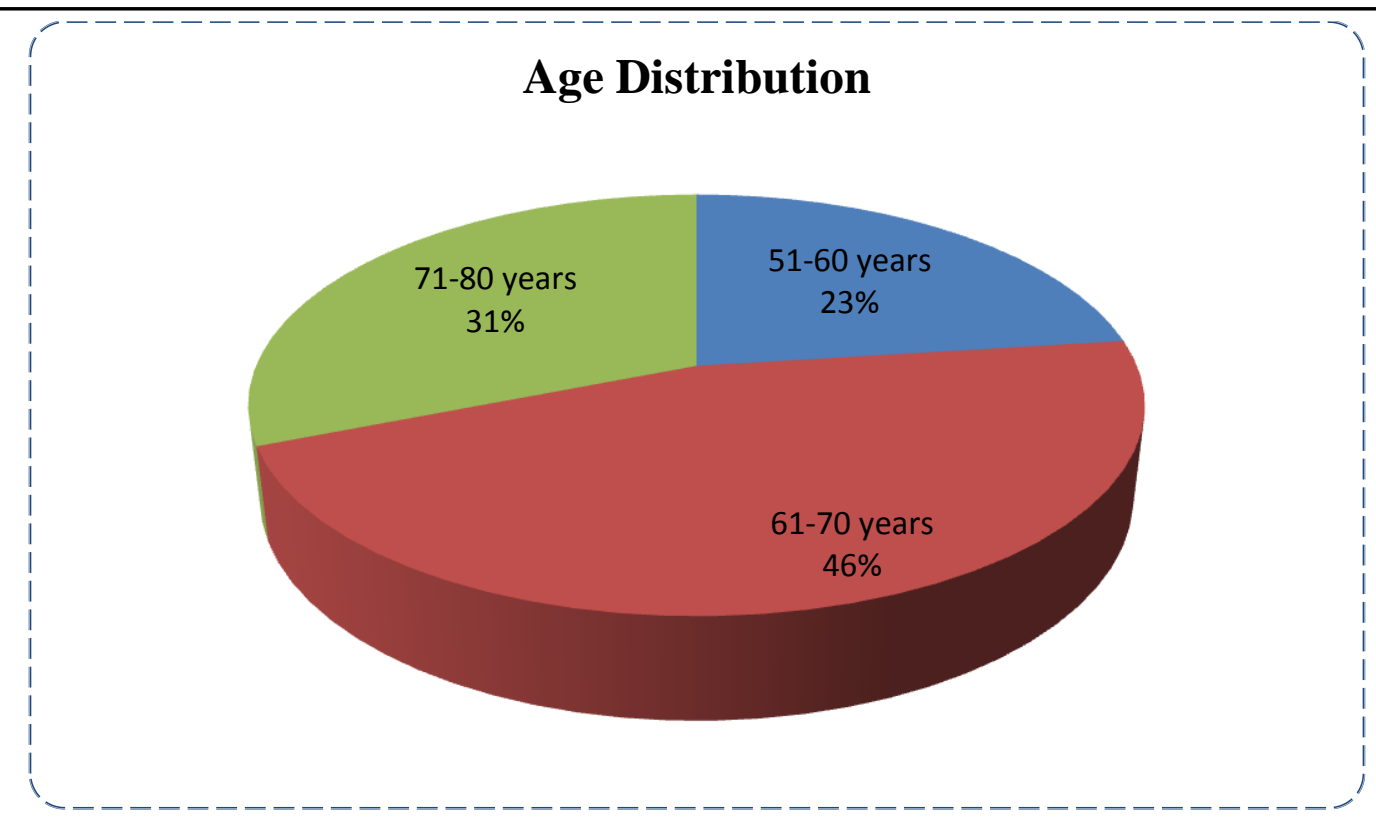

In this study $64 \%$ of patients were male and $36 \%$ were female. It's due to lack of awareness of cataract surgery in female population compared to male population in Srikakulam district, Andhra Pradesh.

\section{Gender Distribution}

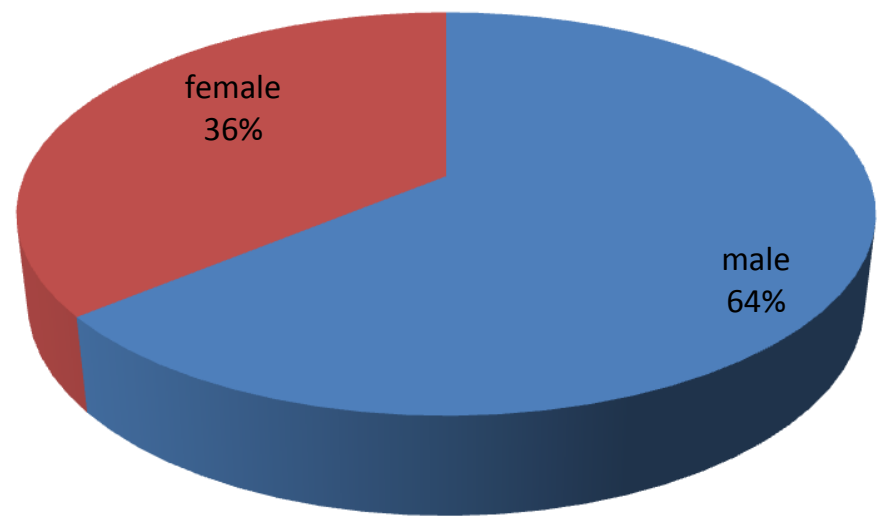

After 6 weeks of surgery, a detailed examination was done to check visual acuity uncorrected and best corrected. Details of which are as below.

\section{Uncorrected Visual Acuity After 6 Weeks}

\begin{tabular}{|l|c|c|}
\hline Visual acuity & No. of patients & percentage \\
\hline $6 / 9-6 / 12$ & 25 & $25 \%$ \\
\hline $6 / 12-6 / 18$ & 48 & $48 \%$ \\
\hline$>6 / 18$ & 27 & $27 \%$ \\
\hline
\end{tabular}

\begin{tabular}{|l|c|c|c|c|}
\hline Visual acuity & $\begin{array}{c}\text { Chevron } \\
\text { group }\end{array}$ & Frown group & Boat group & $\begin{array}{c}\text { Straight } \\
\text { group }\end{array}$ \\
\hline $6 / 9-6 / 12$ & $8(8 \%)$ & $6(6 \%)$ & $6(6 \%)$ & $5(5 \%)$ \\
\hline $6 / 12-6 / 18$ & $12(12 \%)$ & $13(13 \%)$ & $12(12 \%)$ & $11(11 \%)$ \\
\hline$>6 / 18$ & $5(5 \%)$ & $6(6 \%)$ & $7(7 \%)$ & $9(9 \%)$ \\
\hline
\end{tabular}




\section{Uncorrected Visual acuity}

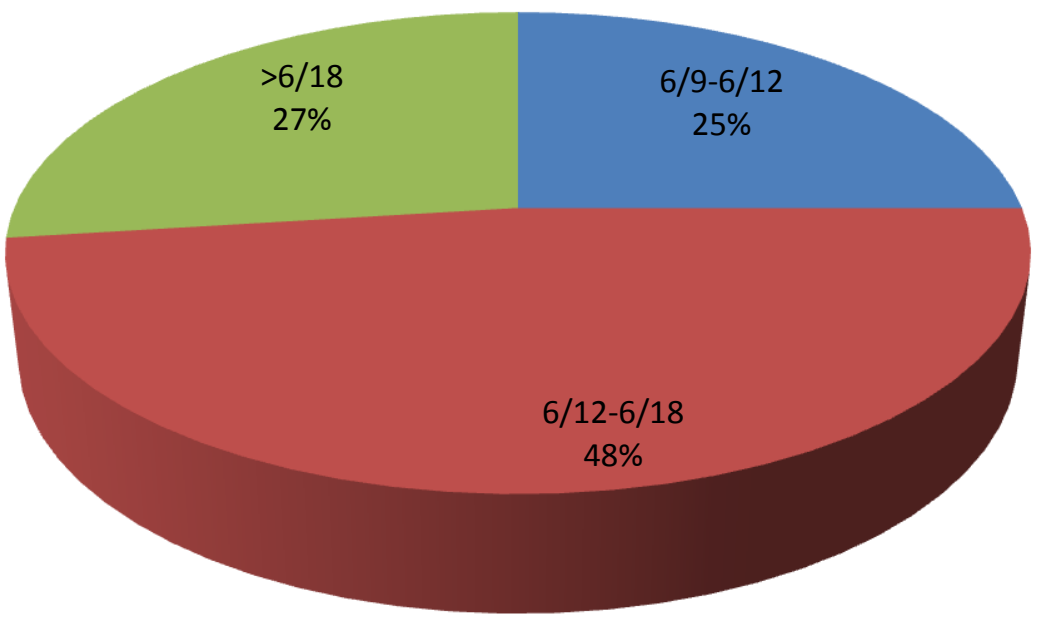

Best Corrected Visual acuity after 6 Weeks

\begin{tabular}{|l|c|c|}
\hline Visual acuity & No. of patients & percentage \\
\hline $6 / 6-6 / 9$ & 89 & $89 \%$ \\
\hline $6 / 9-6 / 12$ & 6 & $6 \%$ \\
\hline $6 / 12-6 / 18$ & 3 & $3 \%$ \\
\hline$>6 / 18$ & 2 & $2 \%$ \\
\hline
\end{tabular}

\begin{tabular}{|l|c|c|c|c|}
\hline Visual acuity & $\begin{array}{c}\text { Chevron } \\
\text { group }\end{array}$ & Frown group & Boat group & $\begin{array}{c}\text { Straight } \\
\text { group }\end{array}$ \\
\hline $6 / 6-6 / 9$ & $25(25 \%)$ & $23(23 \%)$ & $22(22 \%)$ & $19(19 \%)$ \\
\hline $6 / 9-6 / 12$ & - & $2(2 \%)$ & $2(\%)$ & $2(2 \%)$ \\
\hline $6 / 12-6 / 18$ & - & - & $1(1 \%)$ & $2(2 \%)$ \\
\hline$>6 / 18$ & - & - & - & $2(2 \%)$ \\
\hline
\end{tabular}

\section{Best corrected Visual acuity}

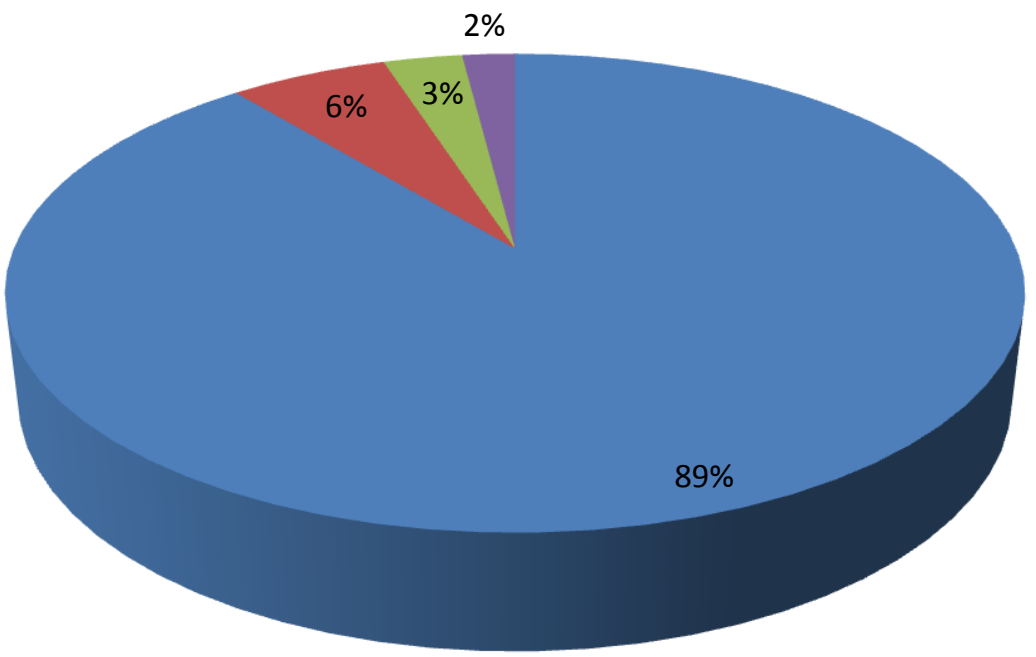

- 6/6-6/9

6/9-6/12

$6 / 12-6 / 18$

- $>6 / 18$ 
On detailed examination there were astigmatism noted after 6 weeks of surgery. There were

\section{Astigmatism Found In Different Incisions}

\begin{tabular}{|l|c|c|c|c|c|}
\hline & $0.0-0.5 \mathrm{D}$ & $0.6-1.0 \mathrm{D}$ & $1.1-1.5 \mathrm{D}$ & $1.6-2.0 \mathrm{D}$ & $>2.1 \mathrm{D}$ \\
\hline Chevron & $12(48 \%)$ & $9(36 \%)$ & $4(16 \%)$ & - & - \\
\hline Frown & $6(24 \%)$ & $7(28 \%)$ & $11(44 \%)$ & $1(4 \%)$ & - \\
\hline Boat & $5(20 \%)$ & $7(28 \%)$ & $9(36 \%)$ & $3(12 \%)$ & $1(4 \%)$ \\
\hline Straight & $1(4 \%)$ & $6(24 \%)$ & $10(40 \%)$ & $6(24 \%)$ & $2(8 \%)$ \\
\hline
\end{tabular}

The chi-square statistic is 20.7825 . The $\mathrm{p}$-value is .053657 . The result is not significant at $\mathrm{p}<.05$

\section{Discussion}

In our study Chevron Group had minimal astigmatism. $48 \%$ of people had astigmatism $<0.5 \mathrm{D}$ which are uncorrected Visual acuity after 6 weeks of surgery. It was corrected with spectacle correction completely. $36 \%$ people had 0.5 to $1 \mathrm{D}$ and only $16 \%$ patients had visual acuity $>1 D$. This is correlated with some other studies. In Randeri et $\mathrm{al}^{13}$ study astigmatism <1D was $57.14 \%$. As per study Jauhari $\mathrm{N}$ et $\mathrm{al}^{14}$ visual acuity of $<1 \mathrm{D}$ was 47.6\%. The reason for this is $\mathrm{V}$ shaped Chevron incision is geometrically more stable thereby causing minimal sliding of tip of incision.

In our study frown incision showed slightly higher astigmatism compared to chevron incision. 52\% patients here showed <1D astigmatism where maximum were between 0.5-1 D. similar findings were seen in study conducted by Jha and vats ${ }^{15}$ which report $85.5 \%$ of patients with astigmatism up to $1 \mathrm{D}$, with only $8.7 \%$ cases having astigmatism more than 2 D. similarly another study conducted by jauhari $\mathrm{N}$ at $\mathrm{al}^{14} 57.9 \%$ of patients showed induced astigmatism of <1D. Minimum surgically induced astigmatism with Chevron incision in our study is supported by previous studies of Rohatgi et $\mathrm{al}^{16}$ and Randeri et al ${ }^{13}$.

In our study Boat shaped incision showed almost similar to frown shaped incision. $48 \%$ patients had astigmatism of <1D followed by $48 \%$ patients with 1-2D. Maximum patients (36\%) were seen in 1.1-1.5D. this was almost similar to frown incision even though frown was slightly better as per our studies.

Straight incision was also studied and outcome is evaluated. It shows only $28 \%$ patients with astigmatism <1D. $40 \%$ patients show astigmatism significant differences noted in different types of incisions.
1.1-1.5D and 24\% showed astigmatism 1.5-2D. These findings show straight incision causes maximum astigmatism among all the four incisions studied.

This study compares 4 types of incisions for the manual small incision cataract surgery. This study had limitation of taking small population of patients ( 25 in each group) so can't conclude the findings as it may vary when large population of patients and long term effects are studied.

\section{Conclusion}

This study concludes that,

Among all the four incisions namely Chevron incision, Frown incision, Boat shaped incision and straight incision minimal astigmatism was seen in chevron incision type. It was significantly lower compared to other incision types. Frown incision and boat shaped incision were almost similar and marginally frown incision was better compared to boat shaped incision. The difference is not significant due to smaller population of patients are studied and needs more research to prove it. Straight incision caused significantly higher astigmatism with maximum patients had 1-2 D astigmatism.

This study concludes in manual small incision cataract surgery type of incision done significantly changes the outcome in terms of astigmatism and uncorrected visual acuity. Even though chevron incision causes significantly less astigmatism, its less accepted among surgeons due to its steep learning curve. It was seen frown incision or boat shaped incision was preferred over chevron incision among surgeons due to its ease of learning and performing with relatively low surgically induced astigmatism. 
Bibliography

1. Zawar SV, Gogate P. Safety and efficacy of temporal manual smallincision cataract surgery in India. Eur $\mathbf{J}$ Ophthalmol 2011;21(6):748-753

2. Tabin G, Chen M, Espandar L. Cataract surgery for the developing world. Curr OpinOphthalmol2008;19(1):55-59

3. Ruit S, Tabin G, Chang D, Bajracharya L, Kline DC, Richheimer W, Shrestha M, Paudyal G. A prospective randomized clinical trial of phacoemulsification manual sutureless small-incision extra capsularcataract surgery in Nepal. Am J Ophthalmol 2007;143(1):32-38

4. Khanna R, Pujari S, Sangwan V. Cataract surgery in developing countries. Curr Opin Ophthalmol 2011;22(1):10-14

5. Pershing S, Kumar A. Phacoemulsification versus extracapsular cataractextraction: where do we stand? Curr Opin Ophthalmol 2011;22(1):37-42

6. Gogate P, Deshpande M, Nirmalan PK. Why do phacoemulsification? Manual small-incision cataract surgery is almost as effective, but less expensive. Ophthalmology 2007;114(5):965-968

7. Haripriya A, Chang DF, Reena M, Shekhar M. Complication rates of phacoemulsification and manual smallincision cataract surgery at Aravind Eye Hospital. J cataract refract surg2012;38 (8):1360-1369.

8. Gokhale NS, Sawhney S. Reduction in astigmatism in manual smallincision cataract surgery through change of incision site. Indian J Ophthalmol2005;53(3):201203.

9. Reddy B, Raj A, Singh VP. Site of incision and corneal astigmatism in conventional SICS versus phacoemulsification. Ann Ophthalmol (Skokie) 2007;39(3):209-216

10. Ale JB. Surgically induced astigmatism of small incision cataractsurgery. Nepal J ophthalmol2012;4(2):343
11. Guan CY, Xiao TT. Astigmatism following small incision cataractextraction through superotemporal incision. Eye sci 2012;27(2):94-97.

12. Mallik VK, Kumar S, Kamboj R, Jain C, Jain K, Kumar S. Comparisonof astigmatism following manual small incision cataract surgery: superiorversus temporal approach. Nepal J Ophthalmol2012;4(1):54-58

13. Randeri JK, Desai RJ, Mehta FS, Billore OP, Gupta A, Kukadia G. Incision induced astigmatism-a comparative study of Chevron incision and Frown incision in SICS. AIOS Proceedings 2008

14. Jauhari N, Chopra D, Chaurasia RK, Agarwal A. Comparison ofsurgically induced astigmatism in various incisions in manual smallincision cataract surgery.Int $\mathbf{J}$ Ophthalmol 2014;7(6):1001-1004

15. Jha KN, Vats DP. Manual small incision cataract surgery: experience at a military hospital. : MJAFI 2006;62(3):212-215

16. Rohatgi J, Gupta VP, Sangma D. A prospective randomized comparativestudy of manual SICS using $6 \mathrm{~mm}$ frown versus $5 \mathrm{~mm}$ modified ChevronIncision. AIOS Proceedings 2008.

17. randomization was done through NCBI approved site www.graphpad.com/quickcals/randomize2 I

List was made and put up. Every new patient came to hospital, strictly patient was assigned as per the chart. It was overlooked personally by us to keep randomization unbiased. 